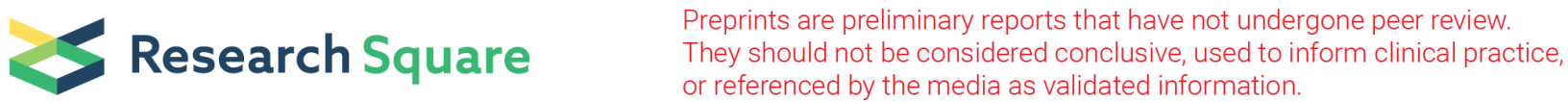

\section{Arthroscopic reconstruction of anterior cruciate ligaments with allograft: Single-tunnel double-bundle versus single-tunnel single- bundle}

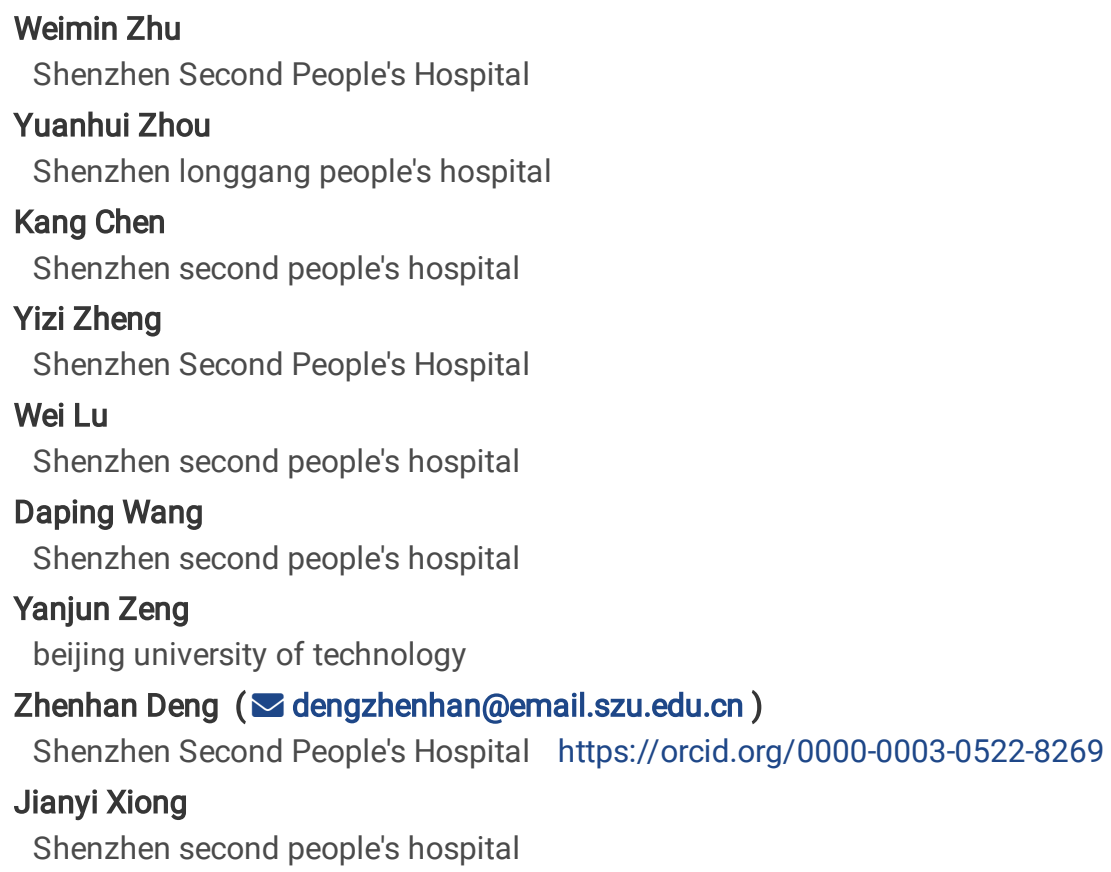

\section{Research article}

Keywords: Arthoscopy, anterior cruciate ligament, double-bundle reconstruction, anterior tibialis tendon, allograft

Posted Date: November 6th, 2020

DOI: https://doi.org/10.21203/rs.3.rs-44919/v2

License: (c) (i) This work is licensed under a Creative Commons Attribution 4.0 International License. Read Full License 


\section{Abstract}

Purpose: Arthroscopic reconstruction of anterior cruciate ligament (ACL) commonly adopted single-tunnel single-bundle (STSB) or doubletunnel double-bundle (DTDB) methods. Though single-tunnel double-bundle (STDB) has been used in clinical practice, the efficacy remains unclear. The objective of this study is to compare the clinical results of ACL reconstruction using the STDB and STSB techniques.

Methods: Between March 2010 to June 2013, 78 patients with ACL rupture underwent arthroscopic STDB reconstruction (42 cases) or STSB reconstruction (36 cases) using anterior tibialis tendon allografts in our department. IKDC, Lysholm and Tegner scores were used to evaluate the subjective function of the knee joint during the postoperative follow-up. In addition, the Lachman test and pivot shift test were used to objectively assess the stability of the knee.

Results: The average follow-up time is $24.2 \pm 5.7$ months in the STDB group, and $24.8 \pm 6.6$ months in the STSB group. Patients in both groups recovered to preoperative sports level with few complications. The postoperative Lysholm, IKDC, Tegner scores, and knee joint stability were significantly improved compared to preoperative status in both groups $(P<0.05)$. However, no statistically significant difference was observed between the two groups at the final follow-up $(P>0.05)$, except for the improvement of pivot shift test positive rate in the STDB group compared with STSB group $(P<0.05)$.

Conclusion: Both techniques can be used to restore the stability and function of the knee joint with satisfactory short-term efficacy, and STDB showed better rotational stability than STSB technique, indicating the STDB technique may also considered a reliable method for $A C L$ reconstruction.

\section{Introduction}

Anterior cruciate ligament $(\mathrm{ACL})$ is the main stabilizing structure of the knee, which resists to the anterior translation and maintains the forward and rotating stabilities [1,2]. It is generally considered to include two functional bundles; the anteromedial (AM) and the posterolateral $(P L)$ bundles, and each of the two primary $A C L$ bundles has a unique function $[3,4]$. The AM bundle and the PL bundle provide anteroposterior and rotational stability to the knee joint [5]. At present, the main ACL surgical procedures include the single-tunnel single-bundle (STSB) and double-tunnel double-bundle (DTDB) reconstructions [6,7]. However, a DTDB is difficult to perform for surgeons and more traumatic for patients compared to STSB reconstruction. It requires a long operative time, tunnel positioning is prone to error, the risk of lateral femoral condyle and bone bridge fractures is increased, and challenging in revision surgery [8,9].

Taking these factors into account, some surgeons have explored a single-tunnel double-bundle (STDB) reconstruction with the goal of restoring the anatomical double-bundle (DB) structure of the ACL within a single tunnel [10-13]. This technique overcomes the shortcomings of both DTDB and STSB reconstruction (i.e., restores anteroposterior and rotational stability without the drawbacks of DTDB reconstructions). Previous publications also reported a DB ACL reconstruction technique with one femoral and two tibial tunnels and achieved good rotational stability in cadaveric knees [14,15]. Duncan et al reported a fresh-frozen porcine knees study with 40 samples and concluded biomechanical advantage with no potential deleterious side effects for fixation of the ACL with a double-tunnel technique on the tibial side [16].

However, no patient outcome data were reported. In this study, we reviewed clinical data of 78 patients with ACL rupture undergoing arthroscopic STDB (one femoral, two tibial tunnels and two bundles) or STSB (one femoral, one tibial tunnel and one bundle) reconstruction from March 2010 to June 2013 and compared the outcomes of the two surgical procedures, in order to provide evidence for the STDB ACL reconstruction theory.

\section{Material And Methods}

\section{Subjects}

This retrospective study was approved by the ethics committee of Shenzhen Second People's Hospital, and all patients gave informed consent preoperatively. Patients who underwent primary ACL reconstruction using anterior tibialis tendon allografts in our department from March 2010 to June 2013 were reviewed. Patients were included if they met the following criteria: 1) 18 years of age or over; 2) primary ACL surgery; 3) no concomitant ligament injury; 4) unilateral ACL injury; 5) no previous surgery on the effected knee, 6), no chondral lesion worse than Outerbridge grade $2 ; 7$ ) clinically and magnetic resonance imaging (MRI) confirmed ACL rupture.

Exclusion criteria included: 1) damage of multiple ligaments or injury of articular cartilage; 2) radiographic evidence of Kellgren-Lawrence over grade or osteoarthritis and/or severe osteoporosis; 3) bilateral ACL injuries; 4) partial ACL rupture; 5) concomitant total or subtotal 
meniscectomy; 6) young patients with unclosed growth plates.

Overall, there were 78 patients met the inclusion criteria in total. The time between injury and surgery ranged from 3 day to 12 months. All patients underwent initial surgery with ACL reconstruction. There were 32 cases with meniscus injury and the menisci were sutured, shaped, or resected according to the type of injury. All of the surgeries were performed by one senior surgeon. And all of the patients were randomly divided into two groups, the STDB reconstruction group $(\mathrm{N}=42)$ and the STSB reconstruction group $(\mathrm{N}=36)$.

\section{Surgical procedure}

\section{Allograft Preparation}

The anterior tibialis tendon allografts (Bone Tissue Engineering Library, Shanxi, China) were prepared on a back table after thawing in $37^{\circ} \mathrm{C}$ normal saline. Length of the tendon was measured and doubled on itself, then the ends of tendon are whip stitched for about $35 \mathrm{~mm}$ with No. 2 Fiberwire suture (Arthrex, Naples, FL). The STDB group separated the allograft (24 to $30 \mathrm{~cm}$ ) into AM and PL bundles with a mean length of 12 to $15 \mathrm{~cm}$ (Fig. 1), while in STSB group, the allograft (24 to $30 \mathrm{~cm}$ ) was folded. After weaving, the graft was clamped at either end on the preparation board with $10 \mathrm{lb}$ of tension. The tendon allograft is kept moist until implantation. According to our experience, the anterior tibialis tendon allograft regularly provide a folded diameter over $9 \mathrm{~mm}$.

Surgeries were performed on patients in a supine position with the affected knee flexing at an angle of $90^{\circ}$ to cause the lower leg to naturally droop beside the bed. Epidural anesthesia was given. A tourniquet was applied around the upper thigh. A routine external anterior approach under arthroscopy was performed in order to confirm the diagnosis of torn ACL.

Construction of femur tunnel: The knee was explored by arthoscopy according to convention procedures to identify the diagnosis (Fig. 2A). Both the lateral intercondylar ridge and the lateral bifurcate ridge are important bony landmarks for the femoral attachments of the ACL, and the femoral tunnel was created in the center of the lateral bifurcate ridge but should not surpass the lateral intercondylar ridge. It was drilled through the AM portal with a cannulated reamer using a freehand technique at $120^{\circ}$ of the knee (Fig. 2B).

Creation of tibial tunnels: In the STDB group, the tibial AM tunnel was placed in the anterior part of the footprint and the tibial PL tunnel was in the posterior part of the footprint (Fig. 2C). Both tibia and femoral drills were selected according to the graft diameter. Traction stitches of AM and PL bundles were passed through the end of the Kischner wire. Then, the wire was brought from the tibial tunnels out of the femoral tunnel. The two grafts were introduced to the tibial and femoral tunnels with traction stitches. The AM bundle was positioned in the AM tunnel and the PL bundle was in the PL tunnel. The femoral side secured was by flipping over the Endobutton. After that, the two bundles of the grafts were tightened in the tibial ends. Two hydroxyapatite interference screw with a diameter of $1 \mathrm{~mm}$ larger than the graft were screwed into the two tibial tunnels in $90^{\circ}$ flexion of the knee, respectively (Fig. 2D). In the STSB group, the tibial tunnel was reamed through the AM surface of the tibia at the level of the tibial tubercle, passing through the landmarks of the center of the ACL remnant (Fig. 2E). The graft was first introduced into the tibial tunnel with a guide wire, and then pulled directly into the femoral tunnel and fixed on the femoral side by flipping over the Endobutton (Fig. 2F). On the tibial side, manually tighten the graft and fix it at $30^{\circ} \mathrm{knee}$ flexion by a doorshaped nail (2.3 mm Kirschner's needle). The fixation was then strengthened by using a hydroxyapatite interference screw with a diameter of $1 \mathrm{~mm}$ larger than the graft.

Neither impingement nor cartilage damage was observed under arthroscopy in all patients.

\section{Postoperative treatment and rehabilitation}

Cefoxitin $1 \mathrm{~g}$ bid was taken during postoperative 48 hours to prevent infection for all patients. The affected limb was wrapped with cotton pad for 72 hours. Three-dimensional computed tomography (3D CT) were performed immediately after surgery to evaluate the bone tunnel and fixation, and magnetic resonance imaging (MRI) was applied to check the ligament healing at postopertive 3, 6,12 and 24 months.

Same postoperative rehabilitation plan was applied to both groups. The affected limb was immobilized with adjustable support. Patients were allowed to walk with crutches and while protected by knee braces (the specific walking time was based on whether the meniscus was sutured) at the second day after operation. Patients were encouraged to flex their knees from 0 to $90^{\circ}$ within 2 to 4 weeks, reach $120^{\circ}$ within 6 to 8 weeks. However, they were instructed not to flex the knee over $120^{\circ}$ in the 3 month postoperative period. The braces were worn for at least 2 months. Patients were allowed to swim and ride a bicycle 6 months after the operation, begin jogging 10 months after the operation, and participate in strenuous exercise 18 months after the operation [17].

\section{Observation indicators}


Knee function was assessed by International Knee Documentation Committee (IKDC), Lysholm, and Tegner scores before operation and at follow-up in all patients. The Lachman test and pivot shift test were performed to assess the knee joint stability. A positive Lachman test is defined as: with the knee flexed $20^{\circ}-30^{\circ}$, the tibia is displaced anteriorly relative to the femur with either a soft endpoint or greater than 4 $\mathrm{mm}$ of displacement. The pivot shift test is considered positive if the proximal tibia subluxes anteriorly on the distal femur at about $30^{\circ}$ of flexion.

\section{Statistical analysis}

Data were expressed as mean \pm standard deviation (SD) and analyzed by SPSS 18.0 software (SPSS Inc., Chicago, IL, USA). Independent samples t-test and $\chi 2$ test were done on the general data of patients. Preoperative and postoperative IKDC, Lysholm, Tegner scores, and KT3000 measurements were tested for Mann Whitney $U$ rank. $P<0.05$ was considered statistically significant.

\section{Results}

\section{Subjects}

106 subjects were evaluated and 28 patients were excluded from this study. The demographic characteristics of the included 78 patients were listed in Table 1. There was no statistical difference between the two groups in gender, age, affected sides, injury time interval, complicated with meniscus injury and follow-up time $(P>0.05)$.

The average follow-up period was $24.2 \pm 5.7$ months in STDB group and $24.8 \pm 6.6$ months in STSB group, respectively. All patients recovered their preoperative activity level at the last follow-up. There was no statistically significant difference in complications between the two groups ( $P>0.05)$ : each group reported one case of infection and recover after systematic anti-infection therapy. There are 3 case of STDB group and 2 cases of STSB group had occasional pain and residual subjective joint instability. No stiffness, rejection reaction, graft failure or deep venous thrombosis of the lower extremities was found in both groups. Postoperative 3D CT showed accurate bone tunnel and properly positioned screw, and, MRI showed complete healing in both groups (Fig. 3).

IKDC, Lysholm, and Tegner scores at the last follow-up significantly improved in both groups compared to preoperative status $(P<0.01)$, but there was no significant difference between the two groups preoperatively and at the last follow-up ( $>>0.05$, Table 2$)$.

Preoperatively, positive Lachman test was detected in 36 (positive rate $85.7 \%$ ) and 32 (positive rate $88.9 \%$ ) cases in STDB and STSB groups, respectively ( $P>0.05$, Table 3). And positive pivot shift test test was detected in 29 (positive rate 69.0\%) and 23 (positive rate $63.9 \%$ ) cases in STDB and STSB groups, respectively P>0.05). No significant difference was found between the Lachman test rate at the final follow-up clinical examination ( $P>0.05)$. However, pivot shift test rate in the STDB was significantly lower than the STSB group at the final follow-up $(P<0.01)$.

\section{Discussion}

The results of present study with over 2 years of follow-up showed that the postoperative scores of IKDC, Lysholm and Tegner in both groups were significantly higher than preoperative status, indicating that the knee joint function was recovered after STDB or STSB reconstruction with allograft. Pivot shift test rate in the STDB was significantly improved than the STSB group at the final follow-up. However, other indicators showed no significant difference between the groups at the final follow-up.

With the development of ACL biomechnics and surgical techniques, whether STSB or DTDB reconstruction is proper becomes conversional $[18,19]$. Meredick et al. reported that the STSB reconstruction could restore most of the function (anterior-posterior stability) of the AM bundle, but not the PL bundle. Furthermore, it also failed to restore the rotational stability, leading to relaxation in knee extension [20]. It has been proved that either of two bundles of ACL plays an irreplaceable role. Zantop et al. reported that tibia shifted forward more significantly after transecting the $\mathrm{AM}$ bundle in the knee at $60^{\circ}$ and $90^{\circ}$ flexion and after transecting the $\mathrm{PL}$ bundle in the knee at $30^{\circ}$ flexion [4]. Additionally, when flexing at $0^{\circ}$ and $30^{\circ}$, the knee revolved more significantly after transecting the PL bundle compared to in the normal situation and after transecting the AM bundle. Therefore, it is considered that STSB reconstruction is unable to restore the knee stability, particularly the rotation stability. Some studies indicated no significant difference in the anterioposterior stability between two procedures but a significant superiority in rotation stability in the DTDB procedure than the STSB procedure $[21,22]$.

However, the DTDB reconstruction also has many disadvantages: (1) it requires four tunnels drilled in the femoral condyle and tibial plateau, increasing the surgical difficulty and surgical time; (2) more bone tunnels also increase the difficulty in positioning in the tunnel opens and consequently, higher skill level is required for operators; (3) bone bridges between tunnels may break up during the surgery, 
inducing the fixation failure; (4) the knee loses much bone mass, which is not beneficial for ACL reconstruction and revision in the late stage and associated with the risk of fracture of femoral fibular condyle and increasing incidence of impingement syndrome [23].

For this reason, a novel surgical procedure, the STDB reconstruction, is developed to provide an alternative treatment method for restoring the normal anatomic structures and biomechanical properties [24]. It is to reconstruct two bundles (AM and PL) of different functions by separating the two bundles of ligament in the tunnel, which is characterized by simple operation, ability of simulating the DTDB anatomic property and excellent anterioposterior and rotation stability, shortening surgical time and decreasing difficulty and risk of DBDT pattern $[25,26]$. Gadikota et al. measured biomechanical properties of the cadaveric knee specimen in the action of forward-load and found that compared to the STSB reconstruction, the STDB was more equal to normal ACL with regard to biomechanical properties [21].

In this study, clinical outcomes, Tegner, Lysholm scores and IKDC grades were compared between the STSB and STDB reconstruction procedures. Although no significant difference on clinical functional scores and lachman test positive rate were noted, the STDB technique showed significantly lower pivot shift test positive rate compared with STDB group at the last follow-up, indicating achieving better rotational stability via the STDB technique. Li et al compared the therapeutic effects of bioabsorbable interference screws with endobuttons fixation of the grafts in treatment of ACL rupture using STDB technique. No significant difference in Lysholm, IKDC and Larson scoring at the last follow-up [14]. In their later cadaveric study, they performed biomechanical analysis comparing STDB and STSB reconstruction with both two fixation methods. The results indicated that similar anterior-posterior stability was found between these two technique, while the STDB technique exhibited better rotational stability tested at $30^{\circ}$ and $45^{\circ}$ of knee flexion than the STSB group, which was in accordance with our findings [15]. In a fresh-frozen porcine knees study conducted by Duncan et al, no significant difference in maximum failure load was found between the two technique. However, stiffness of the tibial tunnel complex was significantly higher in the STDB group [16]. Therefore, our results added clinical practice evidence for the application of this new technique.

There are several limitations in this study. Firstly, this study was retrospectively carried out. More prospective research including randomized controlled trials should be performed to provide more evidence. Secondly, the sample size is relatively small with relatively short follow-up. More cases will be added and long-term detection should be conducted in the future. Besides, previous cadaveric studies reported that STDB technique may achieve better rotational stability [14,15]. However, the quantitative data for the difference between the two methods could collect from patients. Only clinical physical examination and patients' objective feeling of stability were measured in this study. What is more, several ACL injury patients were accompanied by meniscus injury that might hampered the reliability of the result. More cases will be added and these confounding factors will be excluded to achieve more convincing results. Last but not least, we didn't compare the clinical outcome between STDB and DTDB methods, which will be the future direction of our works.

In conclusion, the stability and function of knee joint can be restored well using either STDB and STSB ACL reconstuction with allograft and STDB technique showed superior rotation stability at the final follow-up, and the short-term curative effect is satisfactory. However, it is still developed in the early stage and many problems should be resolved, such as the tunnel positioning, the most proper fixation angle between the two bundles and accurate positioning device and double-bundle separating device.

\section{Abbreviations}

3D CT: three-dimensional computed tomography; ACL: anterior cruciate ligament; AM: anteromedial; DB: double-bundle; DTDB: doubletunnel double-bundle; IKDC: International Knee Documentation Committee; MRI: magnetic resonance imaging; PL: posterolateral; STDB: single-tunnel double-bundle; STSB: single-tunnel single-bundle; SB: single-bundle; SD: standard deviation.

\section{Declarations}

\section{Ethics approval and consent to participate}

The present study was approved by the ethics committee of Shenzhen Second People's Hospital.

\section{Consent for publication}

Not applicable.

Availability of data and materials

All data generated or analysed during this study are included in this published article.

\section{Competing interests}


The authors declare that they have no competing interests.

\section{Funding}

This study was supported by the National Natural Science Foundation of China $(81672234,81902303,81902682)$, Guangdong Basic and Applied Basic Research Foundation (2020A151501048), Shenzhen Science and Technology Project (GJHZ20180416164801042, JCYJ20180305124912336), Science and Technology Commission of Shanghai Municipality (Shanghai Sailing Program 19YF1408900), and Clinical Research Project of Shezhen Second People's Hospital (20173357201814, 20203357007, 20203357028).

\section{Authors' Contributions}

WZ performed the experiments, data collection and analyses. YZ performed the experiments, data collection and analyses. KC performed the experiments, data collection and analyses. YZ performed data collection. WL performed data collection. DW performed data analyses. YZ performed data analyses. ZD performed the experiments, data collection and analyses and manuscript preparation. JX contributed to study design.

\section{Acknowledgements}

Not applicable.

\section{References}

1. Kraeutler MJ, Wolsky RM, Vidal AF, Bravman JT. Anatomy and Biomechanics of the Native and Reconstructed Anterior Cruciate Ligament: Surgical Implications. J Bone Joint Surg Am 2017;99(5):438-445.

2. Anderson CJ, Westerhaus BD, Pietrini SD, et al. Kinematic impact of anteromedial and posterolateral bundle graft fixation angles on double-bundle anterior cruciate ligament reconstructions. Am J Sports Med 2010;38(8):1575-83.

3. Girgis FG, Marshall JL, Monajem A. The cruciate ligaments of the knee joint. Anatomical, functional and experimental analysis. Clin Orthop Relat Res 1975(106):216-31.

4. Zantop T, Herbort M, Raschke MJ, Fu FH, Petersen W. The role of the anteromedial and posterolateral bundles of the anterior cruciate ligament in anterior tibial translation and internal rotation. Am J Sports Med 2007;35(2):223-7.

5. Buoncristiani AM, Tjoumakaris FP, Starman JS, Ferretti M, Fu FH. Anatomic double-bundle anterior cruciate ligament reconstruction. Arthroscopy 2006;22(9):1000-6.

6. Sundemo D, Sernert N, Kartus J, et al. Increased Postoperative Manual Knee Laxity at 2 Years Results in Inferior Long-term Subjective Outcome After Anterior Cruciate Ligament Reconstruction. Am J Sports Med 2018;46(11):2632-2645.

7. Hussein M, van Eck CF, Cretnik A, Dinevski D, Fu FH. Prospective randomized clinical evaluation of conventional single-bundle, anatomic single-bundle, and anatomic double-bundle anterior cruciate ligament reconstruction: 281 cases with 3- to 5-year follow-up. Am J Sports Med 2012;40(3):512-20.

8. Tajima T, Yamaguchi N, Nagasawa M, Morita Y, Nakamura Y, Chosa E. Early weight-bearing after anterior cruciate ligament reconstruction with hamstring grafts induce femoral bone tunnel enlargement: a prospective clinical and radiographic study. BMC Musculoskelet Disord 2019;20(1):274.

9. Siebold R, Dehler C, Ellert T. Prospective randomized comparison of double-bundle versus single-bundle anterior cruciate ligament reconstruction. Arthroscopy 2008;24(2):137-45.

10. Caborn DN, Chang HC. Single femoral socket double-bundle anterior cruciate ligament reconstruction using tibialis anterior tendon: description of a new technique. Arthroscopy 2005;21(10):1273.

11. Marcacci M, Molgora AP, Zaffagnini S, Vascellari A, lacono F, Presti ML. Anatomic double-bundle anterior cruciate ligament reconstruction with hamstrings. Arthroscopy 2003;19(5):540-6.

12. Takeuchi R, Saito T, Mituhashi S, Suzuki E, Yamada I, Koshino T. Double-bundle anatomic anterior cruciate ligament reconstruction using bone-hamstring-bone composite graft. Arthroscopy 2002;18(5):550-5.

13. Kubo T, Hara K, Suginoshita T, et al. Anterior cruciate ligament reconstruction using the double bundle method. J Orthop Surg (Hong Kong) 2000;8(2):59-63.

14. Ping LW, Bin S, Rui Y, Yang S, Zheng ZZ, Yue D. Arthroscopic ACL reconstruction with reverse "Y"-plasty grafts and fixation in the femur with either a bioabsorbable interference screw or an Endobutton. Knee 2012;19(2):78-83. 
15. Li W, Song Y, Song B, et al. Comparison of anterior cruciate ligament reconstruction methods between reverse "Y" plasty reconstruction and traditional single-bundle technique-A cadaveric study. J Orthop Translat 2018;14:1-7.

16. Meuffels DE, Docter PT, van Dongen RA, Kleinrensink GJ, Verhaar JA, Reijman M. Stiffer fixation of the tibial double-tunnel anterior cruciate ligament complex versus the single tunnel: a biomechanical study. Arthroscopy 2010;26(9 Suppl):S35-40.

17. Zhu W, Wang D, Han Y, Zhang N, Zeng Y. Anterior cruciate ligament (ACL) autograft reconstruction with hamstring tendons: clinical research among three rehabilitation procedures. Eur J Orthop Surg Traumatol 2013;23(8):939-43.

18. Hantes ME, Tsarouhas A, Giakas G, et al. Effect of fatigue on tibial rotation after single- and double-bundle anterior cruciate ligament reconstruction: a 3-dimensional kinematic and kinetic matched-group analysis. Am J Sports Med 2012;40(9):2045-51.

19. Gobbi A, Whyte GP. Anatomic Double-Bundle and Single-Bundle ACL Reconstruction After ACL Rupture Did Not Differ for Quality of Life at 2 Years. J Bone Joint Surg Am 2019;101(10):943.

20. Meredick RB, Vance KJ, Appleby D, Lubowitz JH. Outcome of single-bundle versus double-bundle reconstruction of the anterior cruciate ligament: a meta-analysis. Am J Sports Med 2008;36(7):1414-21.

21. Gadikota HR, Wu JL, Seon JK, Sutton K, Gill TJ, Li G. Single-tunnel double-bundle anterior cruciate ligament reconstruction with anatomical placement of hamstring tendon graft: can it restore normal knee joint kinematics? Am J Sports Med 2010;38(4):713-20.

22. Ahn JH, Lee YS, Ha HC. Anterior cruciate ligament reconstruction with preservation of remnant bundle using hamstring autograft: technical note. Arch Orthop Trauma Surg 2009;129(8):1011-5.

23. Crain EH, Fithian DC, Paxton EW, Luetzow WF. Variation in anterior cruciate ligament scar pattern: does the scar pattern affect anterior laxity in anterior cruciate ligament-deficient knees? Arthroscopy 2005;21(1):19-24.

24. Lee BI, Kwon SW, Kim JB, Choi HS, Min KD. Comparison of clinical results according to amount of preserved remnant in arthroscopic anterior cruciate ligament reconstruction using quadrupled hamstring graft. Arthroscopy 2008;24(5):560-8.

25. Zhu W, Lu W, Han Y, et al. Application of a computerised navigation technique to assist arthroscopic anterior cruciate ligament reconstruction. Int Orthop 2013;37(2):233-8.

26. Xiang X, Qu Z, Sun H, Ma X, Wang W, Huang L. Single-tunnel anatomic double-bundle anterior cruciate ligament reconstruction has the same effectiveness as double femoral, double tibial tunnel: A prospective randomized study. Medicine (Baltimore)

2019;98(11):e14851.

\section{Tables}

Table 1

General information of patients

\begin{tabular}{|c|c|c|c|c|c|c|c|c|c|}
\hline \multirow[t]{2}{*}{ Group } & \multirow[t]{2}{*}{ Number } & \multicolumn{2}{|c|}{ Gender } & \multirow{2}{*}{$\begin{array}{l}\text { Age } \\
\text { (years) }\end{array}$} & \multicolumn{2}{|l|}{ Side } & \multirow{2}{*}{$\begin{array}{l}\text { Injury time } \\
\text { (months) }\end{array}$} & \multirow{2}{*}{$\begin{array}{l}\text { Complicated with meniscus } \\
\text { injury }(n)\end{array}$} & \multirow{2}{*}{$\begin{array}{l}\text { Follow- } \\
\text { up } \\
\text { (months) }\end{array}$} \\
\hline & & Male & Female & & Left & Right & & & \\
\hline $\begin{array}{l}\text { STDB } \\
\text { group }\end{array}$ & 42 & 34 & 8 & $24.6 \pm 4.7$ & 26 & 16 & $5.4 \pm 6.5$ & 18 & $24.2 \pm 5.7$ \\
\hline $\begin{array}{l}\text { STSB } \\
\text { group }\end{array}$ & 36 & 30 & 6 & $25.6 \pm 4.9$ & 24 & 12 & $5.3 \pm 6.7$ & 14 & $24.8 \pm 6.6$ \\
\hline$t / \chi^{2}$ & - & \multicolumn{2}{|c|}{$\chi^{2}=0.437$} & $t=0.273$ & \multicolumn{2}{|c|}{$\chi^{2}=0.658$} & $t=0.374$ & $t=0.063$ & $t=0.650$ \\
\hline$P$ & - & \multicolumn{2}{|l|}{0.591} & 0.786 & \multicolumn{2}{|c|}{0.287} & 0.846 & 0.802 & 0.407 \\
\hline
\end{tabular}

STDB: single-tunnel double-bundle; STSB: single-tunnel single-bundle.

Table 2 Preoperative and last follow-up IKDC, Lysholm and Tegner scores in both groups. 


\begin{tabular}{|c|c|c|c|c|c|c|c|c|c|c|}
\hline \multirow[t]{2}{*}{ Groups } & \multirow[t]{2}{*}{ Number } & \multicolumn{2}{|l|}{ IKDC score } & \multirow{2}{*}{$\begin{array}{l}P \\
\text { value }\end{array}$} & \multicolumn{2}{|c|}{ Lysholm score } & \multirow{2}{*}{$\begin{array}{l}P \\
\text { value }\end{array}$} & \multicolumn{2}{|l|}{ Tegner score } & \multirow{2}{*}{$\begin{array}{l}P \\
\text { value }\end{array}$} \\
\hline & & Preoperative & Follow-up & & Preoperative & Follow-up & & Preoperative & Follow-up & \\
\hline STDB & 42 & $55.46 \pm 16.31$ & $84.75 \pm 9.01$ & 0.000 & $64.7 \pm 4.0$ & $87.0 \pm 2.18$ & 0.000 & $3.07 \pm 1.42$ & $6.19 \pm 1.25$ & 0.000 \\
\hline STSB & 36 & $56.35 \pm 14.74$ & $88.43 \pm 7.96$ & 0.000 & $65.0 \pm 4.9$ & $87.5 \pm 2.33$ & 0.000 & $2.89 \pm 1.53$ & $6.47 \pm 1.09$ & 0.000 \\
\hline $\begin{array}{l}P \\
\text { value }\end{array}$ & - & 0.708 & 0.757 & - & 0.780 & 0.454 & - & 0.572 & 0.697 & - \\
\hline
\end{tabular}

Note: Postoperative follow-up compared with pre-treatment, $\mathrm{P}<0.01$, comparison between follow-up after treatment, $\mathrm{P}>0.05$.

STDB: single-tunnel double-bundle; STSB: single-tunnel single-bundle.

Table 3 Comparison of Lachman test and pivot shift test positive rate preoperatively and at last follow-up in both groups.

\begin{tabular}{|c|c|c|c|c|c|c|c|}
\hline \multirow[t]{2}{*}{ Groups } & \multirow[t]{2}{*}{ Number } & \multicolumn{2}{|c|}{ Lachman test positive rate } & \multirow[t]{2}{*}{$P$ value } & \multicolumn{2}{|c|}{ Pivot shift test positive rate } & \multirow[t]{2}{*}{$P$ value } \\
\hline & & Preoperative & Follow-up & & Preoperative & Follow-up & \\
\hline STDB & 42 & 0.857 & 0.0714 & 0.000 & 0.690 & 0.0714 & 0.000 \\
\hline STSB & 36 & 0.889 & 0.0833 & 0.000 & 0.639 & 0.278 & 0.000 \\
\hline$P$ value & - & $>0.05$ & $>0.05$ & - & $>0.05$ & 0.000 & - \\
\hline
\end{tabular}

Note冈the comparison between the follow-up groups after treatment, $P>0.05$.

STDB: single-tunnel double-bundle; STSB: single-tunnel single-bundle.

\section{Figures}

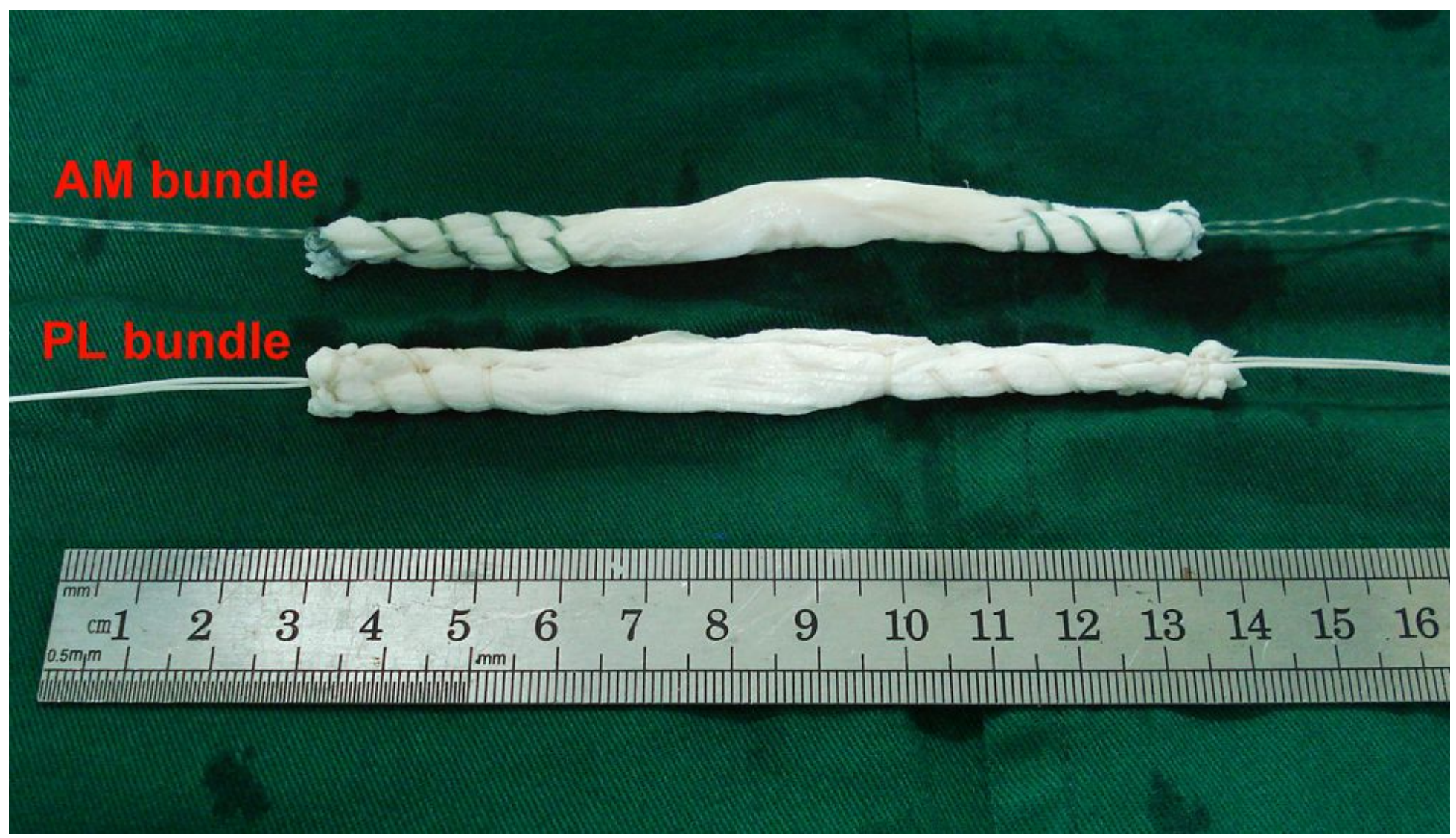


Figure 1

AM and PL bundles prepared using tibialis anterior tendon allograft ready for implantation in STDB group.

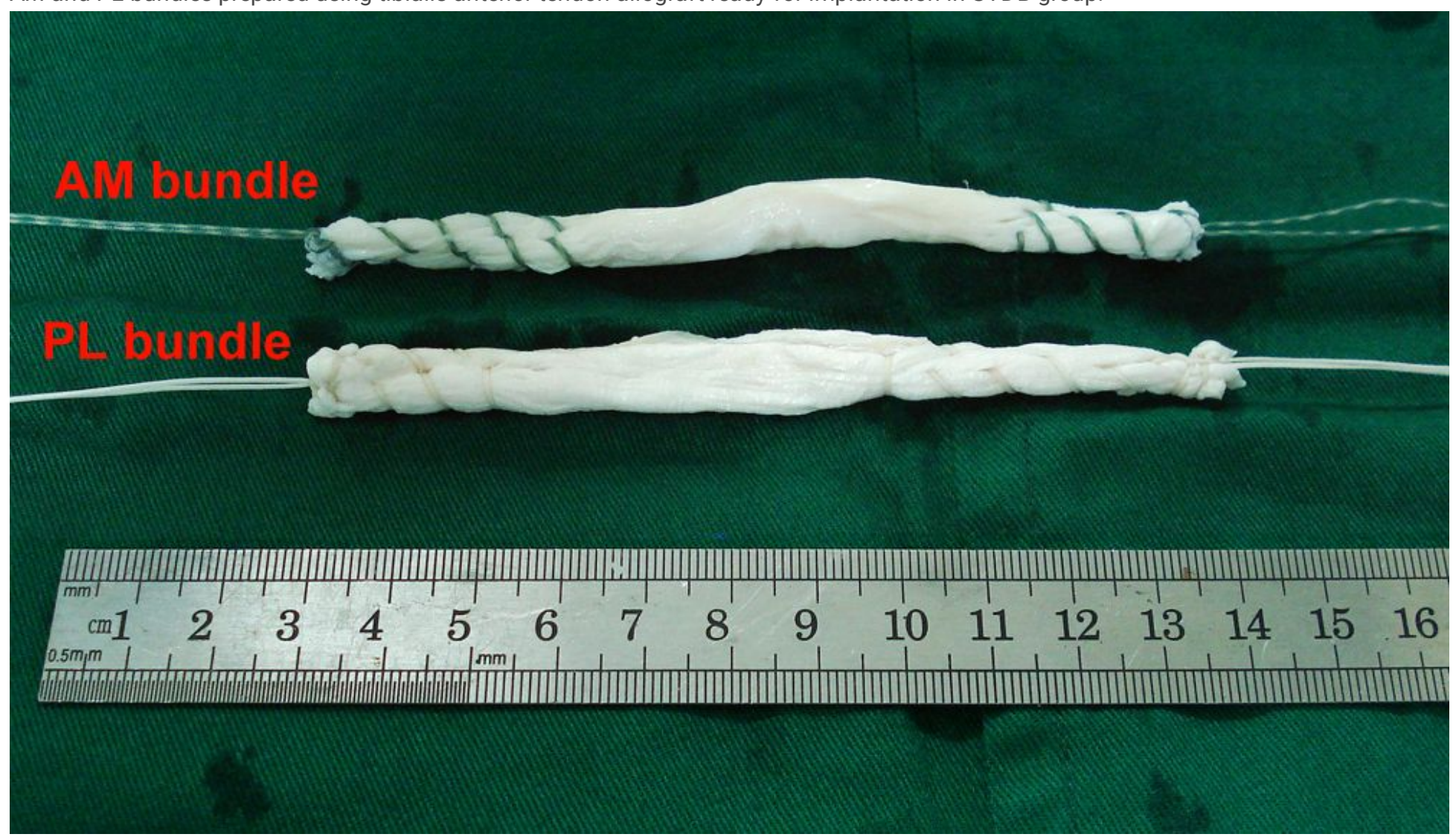

\section{Figure 1}

AM and PL bundles prepared using tibialis anterior tendon allograft ready for implantation in STDB group. 

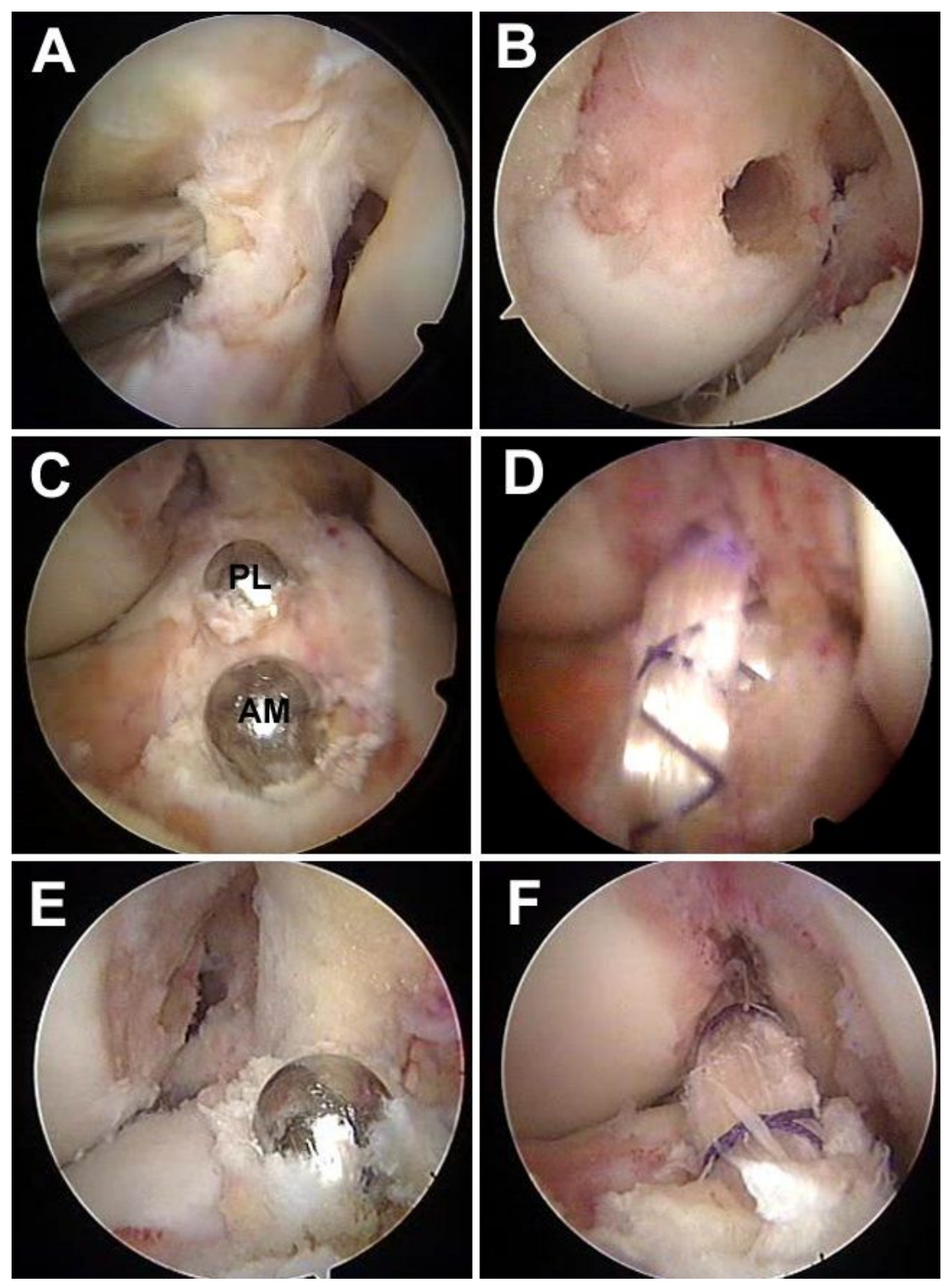

Figure 2

Surgical procedures of STDB and STSB ACL reconstruction under arthroscopy. (A) Diagnose of ACL rupture under arthroscopy. (B) Femoral insertion in both groups. (C) Tibial insertion in STDB group. (D) Reconstructed ACL in STDB group. (E) Tibial insertion in STSB group. (F) Reconstructed ACL in STSB group. Note: AM: anteromedial, PL: posterolateral; STDB: single-tunnel double-bundle; STSB: single-tunnel single-bundle. 

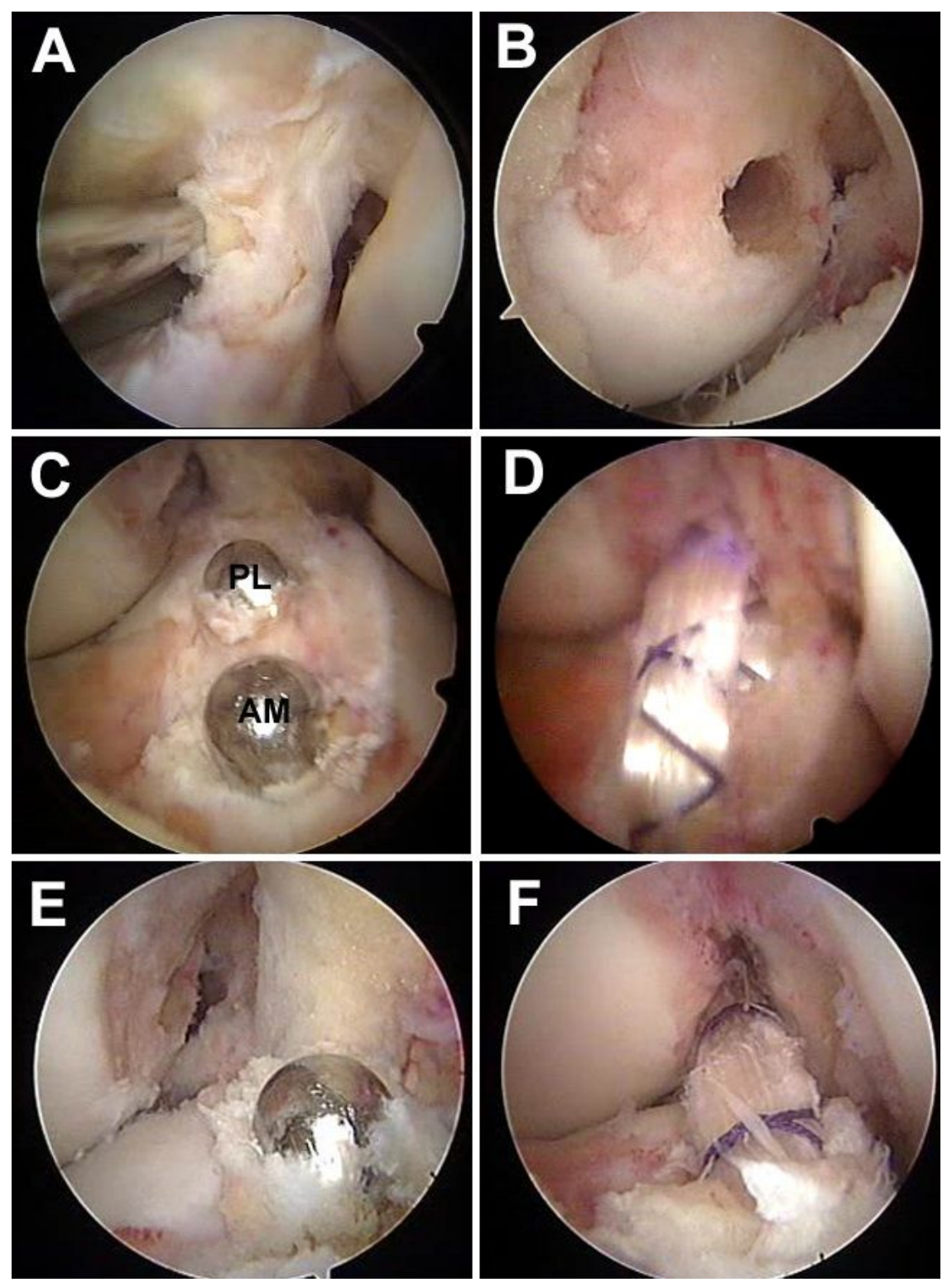

Figure 2

Surgical procedures of STDB and STSB ACL reconstruction under arthroscopy. (A) Diagnose of ACL rupture under arthroscopy. (B) Femoral insertion in both groups. (C) Tibial insertion in STDB group. (D) Reconstructed ACL in STDB group. (E) Tibial insertion in STSB group. (F) Reconstructed ACL in STSB group. Note: AM: anteromedial, PL: posterolateral; STDB: single-tunnel double-bundle; STSB: single-tunnel single-bundle. 


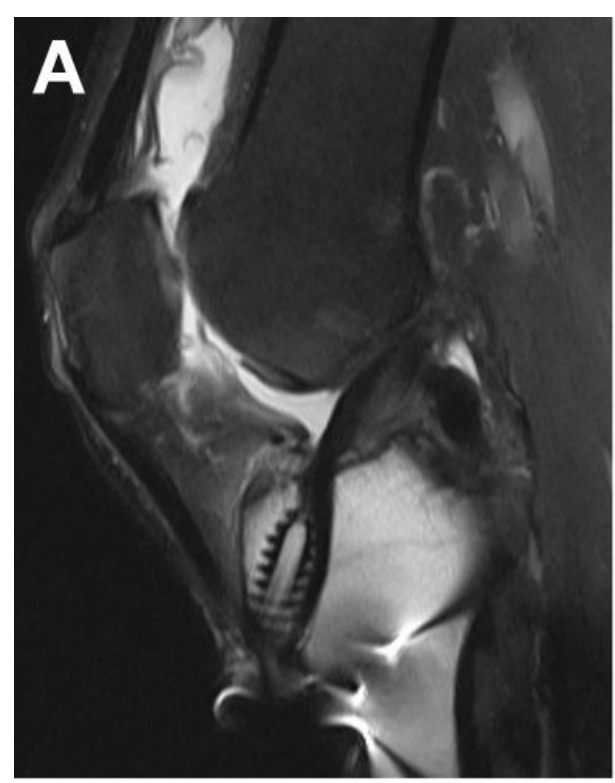

\section{B}
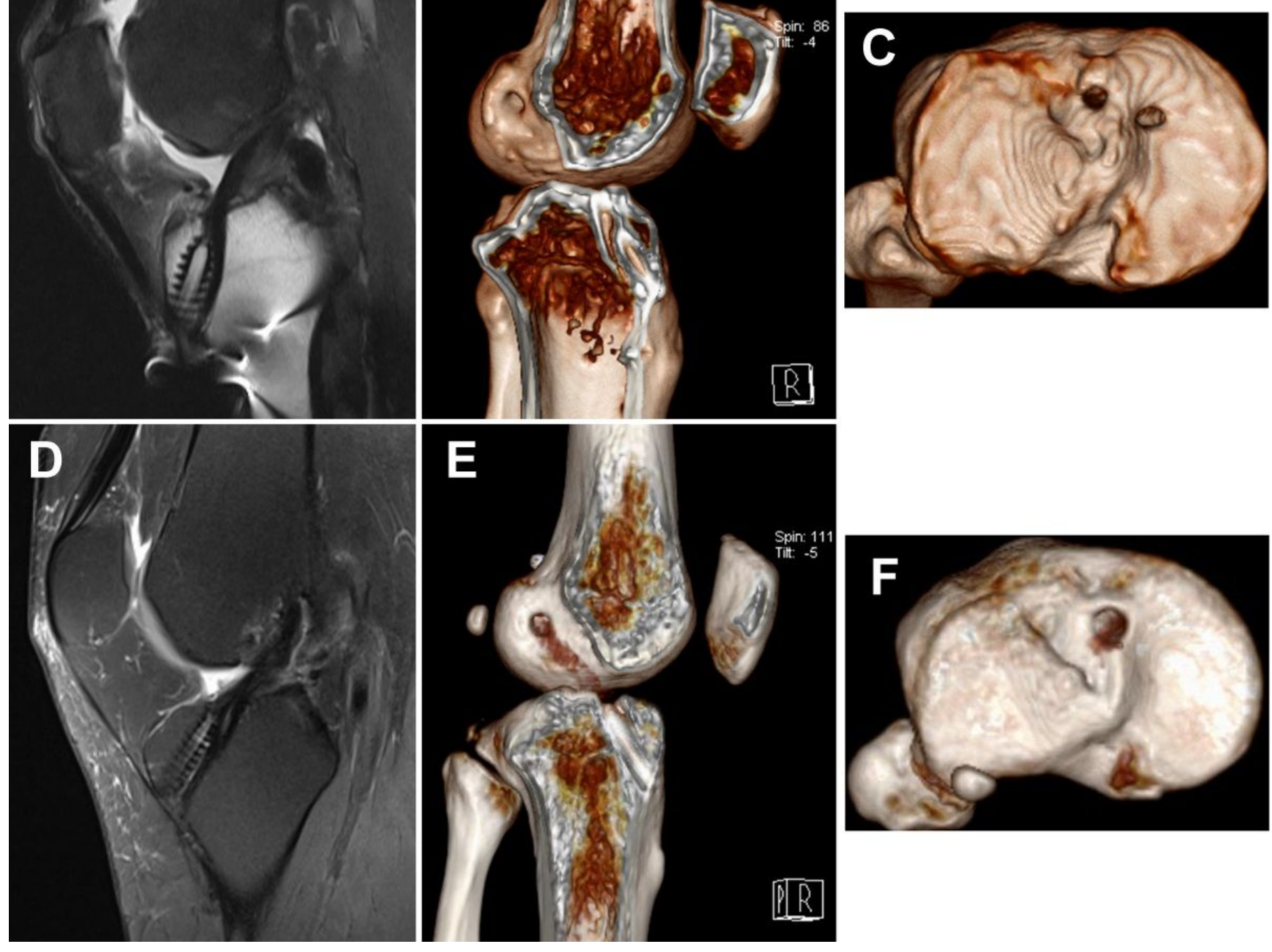

Figure 3

Postoperative radiological examination of STDB and STSB ACL reconstruction after over 2 years. (A) MRI shows grafts healing in STDB group. (B) 3D CT shows tibial femoral and tibial tunnels in STDB group. (C) 3D CT shows tibial sockets in STDB group. (D) MRI shows grafts healing in STSB group. (E) 3D CT shows tibial femoral and tibial tunnel in STSB group. (F) 3D CT shows tibial socket in STSB group. Note: STDB: single-tunnel double-bundle; STSB: single-tunnel single-bundle. 


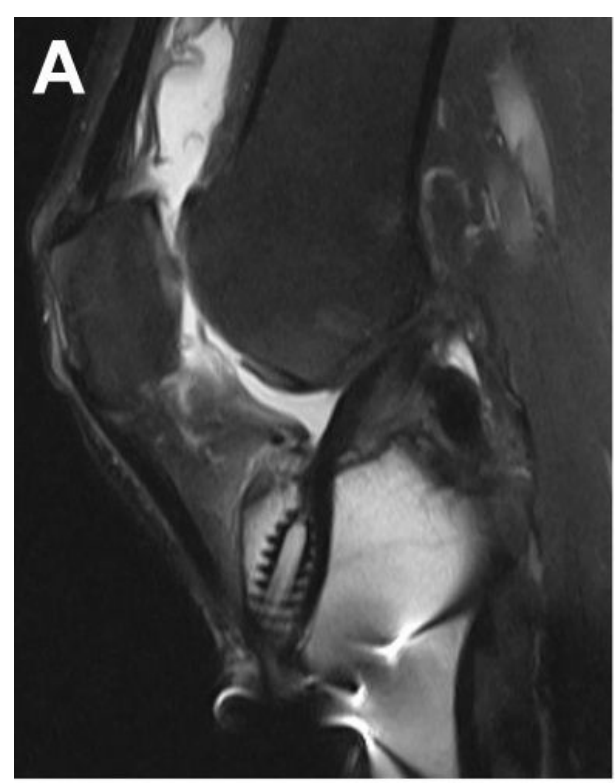

\section{B}
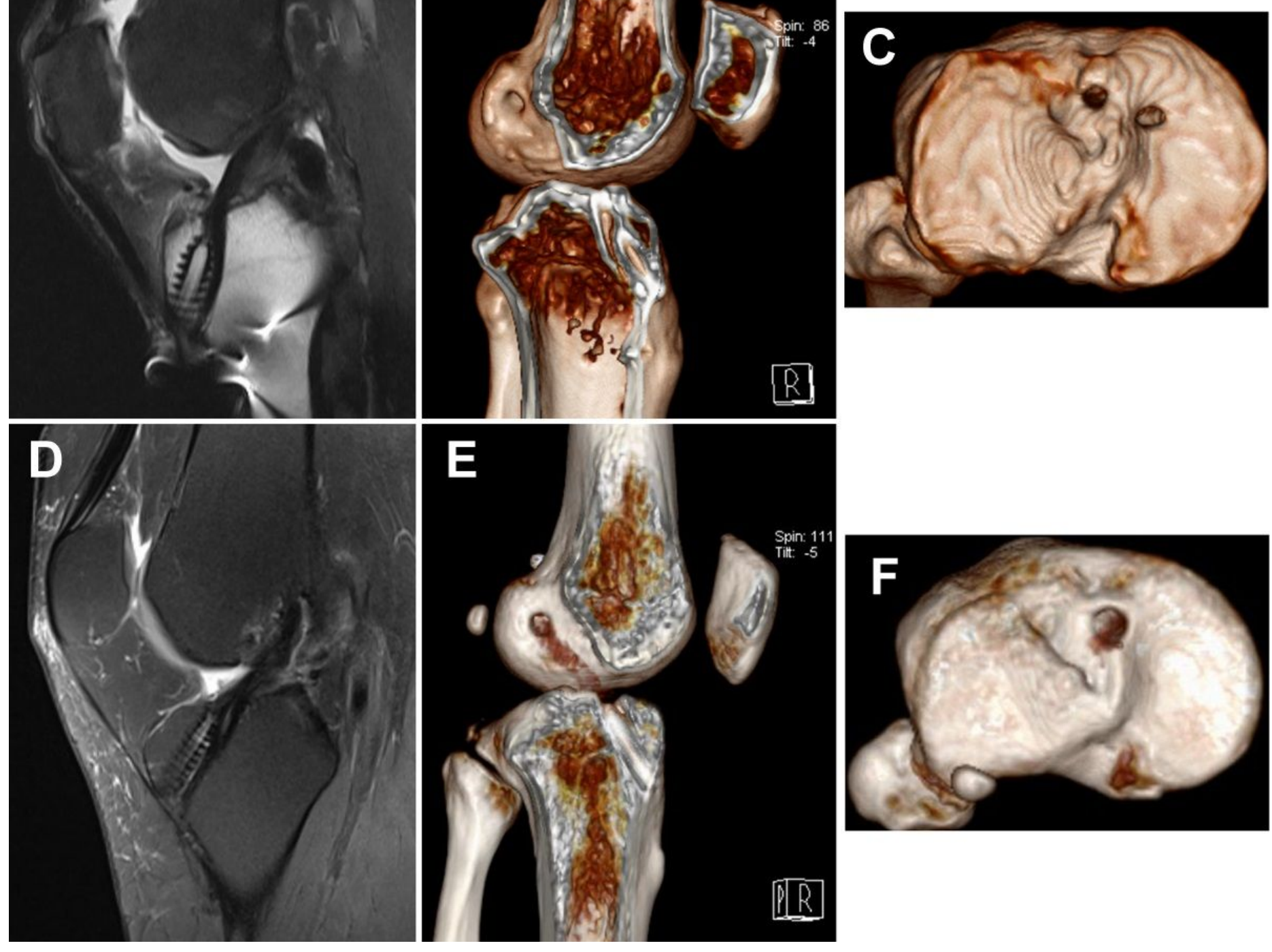

Figure 3

Postoperative radiological examination of STDB and STSB ACL reconstruction after over 2 years. (A) MRI shows grafts healing in STDB group. (B) 3D CT shows tibial femoral and tibial tunnels in STDB group. (C) 3D CT shows tibial sockets in STDB group. (D) MRI shows grafts healing in STSB group. (E) 3D CT shows tibial femoral and tibial tunnel in STSB group. (F) 3D CT shows tibial socket in STSB group. Note: STDB: single-tunnel double-bundle; STSB: single-tunnel single-bundle. 